\title{
The inverse-research law of eye health
}

\author{
John C. Buchan $\mathbb{1}^{1,2} \cdot$ William H. Dean ${ }^{1} \cdot$ Jacqueline Ramke ${ }^{1,3} \cdot$ Matthew J. Burton ${ }^{1,4}$
}

Received: 7 June 2019 / Accepted: 21 June 2019 / Published online: 11 July 2019

(c) The Royal College of Ophthalmologists 2019

Dawson et al. recently observed that, relative to the burden placed on health care services in the UK, some subspecialty areas of ophthalmology are under-represented in the patient-centred research efforts supported by the National Institute for Health Research [1].

At the global level, however, we propose that there is an even larger disparity between the magnitude of the major causes of blindness and the amount of recent research addressing these. Here we use wordclouds (wordcoulds. com; Vianen, The Netherlands) to illustrate this disparity, with the font size proportional to relative frequencies. The relative magnitude of causes of blindness globally is illustrated in Fig. 1, using data from the Global Vision Database [2]. Cataract and uncorrected refractive error dominate, yet countries struggle to identify implementation approaches that work well. In contrast, the global ophthalmic research focus is depicted in Fig. 2. This was quantified by the frequency of Medical Subject Headings (MeSH terms) in articles published in 19 core ophthalmic journals in the 5 years to 2014 [3].

These figures suggest there is an "inverse-research law" in global eye health research, with the leading causes of blindness receiving little attention. This is analogous the inverse-care law, which highlights the well-established observation that those with the greatest health needs often have the least access to services [4].

Low- and middle-income countries carry disproportionately high levels of blindness. These countries invariably have to develop national eye health programs

John C. Buchan

john.buchan@1shtm.ac.uk

1 International Centre for Eye Health, London School of Hygiene and Tropical Medicine, London, UK

2 Leeds Teaching Hospitals NHS Trust, Leeds, UK

3 School of Optometry and Vision Science, University of Auckland, Auckland, New Zealand

4 Moorfields Eye Hospital, London, UK

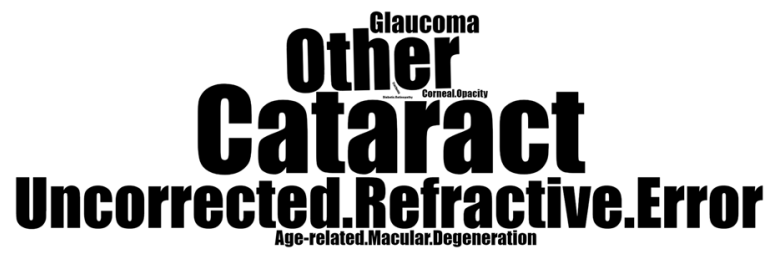

Fig. 1 Relative magnitude of causes of blindness globally

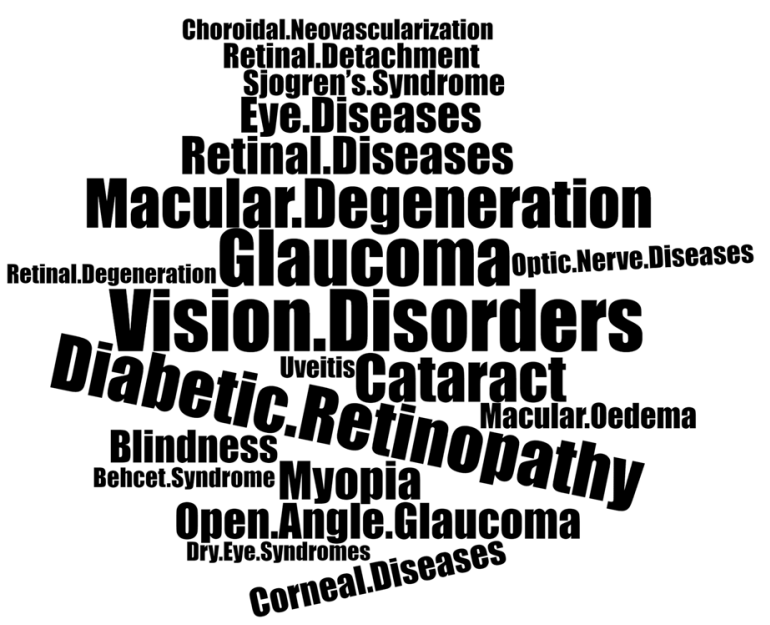

Fig. 2 Relative frequency of MeSH terms from core ophthalmic journal articles

informed by very little context specific evidence to guide implementation of effective approaches [5].

There is clearly a justification for acting in the national self-interest when setting priorities for publicly funded research programmes. However, given the UK's commitment to the United Nations Sustainable Development Goals, with the headline aspiration of "leaving no one behind", we believe the UK has a role to play in supporting low- and middle-income countries to generate the evidence they require to improve eye health in their populations. To achieve this, we call for research funding allocation to aspire to better reflect the causes of the global burden of eye disease. 
Funding JCB is supported by a grant from the Queen Elizabeth Diamond Jubilee Trust through the Commonwealth Eye Health Consortium. WHD is supported by grants from the British Council for the Prevention of Blindness, Ulverscroft Foundation and CBM. JR is a Commonwealth Rutherford Fellow, funded by the UK government through the Commonwealth Scholarship Commission in the UK. MJB is supported by the Wellcome Trust (207472/Z/17/Z).

\section{Compliance with ethical standards}

Conflict of interest The authors declare that they have no conflict of interest.

Publisher's note: Springer Nature remains neutral with regard to jurisdictional claims in published maps and institutional affiliations.

\section{References}

1. Dawson SR, Linton E, Beicher K, Gale R, Patel P, Ghanchi F, et al. Ophthalmology research in the UK's National Health Service: the structure and performance of the NIHR's Ophthalmology research portfolio. Eye (Lond). 2019;33:610-8.

2. Flaxman SR, Bourne RRA, Resnikoff S, Ackland P, Braithwaite T, Cicinelli MV, et al. Global causes of blindness and distance vision impairment 1990-2020: a systematic review and meta-analysis. Lancet Glob health. 2017;5:e1221-34.

3. Boudry C, Denion E, Mortemousque B, Mouriaux F. Trends and topics in eye disease research in PubMed from 2010 to 2014. PeerJ. 2016;4:e1557.

4. Bastawrous A, Hennig BD. The global inverse care law: a distorted map of blindness. Br J Ophthalmol. 2012;96:1357-8.

5. Ramke J, Zwi AB, Silva JC, Mwangi N, Rono H, Gichangi M, et al. Evidence for national universal eye health plans. Bull World Health Organ. 2018;96:695-704. 